\title{
Editorial
}

\section{Carrying capacity}

E ach year IAATO reports an increase in the number of ships taking tourists to the Antarctic and an increase in the number of tourists. Each year the Treaty Parties spend days in discussion on what they should do about this apparently unstoppable development. Since at least some of the Parties subscribe to the idea of "evidence-based decision making" it might be appropriate to ask where is the evidence that they need in order to reach informed judgements?

Their goal has ostensibly always been the protection of the Antarctic environment from unrepairable impacts. However, in all these discussions of a tourism annex, port state jurisdiction, insurance requirements etc there seems to have been little time for consideration of impacts and carrying capacity - perhaps because the data available are so limited? It is true that they have achieved agreements over advisory site management plans for heavily used sites in the Peninsula area but what the key indicators of impact should be and how they should be monitored is missing from the agenda.

It would be unfair to pretend that there had been no attempts to address the impacts question. The tourism companies have to undertake environmental impact assessments every year to get permission to operate their cruises and flights. And the IAATO companies as a whole run a very well organized and policed system with a range of safe guards like boot washing, controls over passengers collecting souvenirs, guides to keep them off vegetation, rules about approaching animals, etc. There have even been workshops to discuss impacts and monitoring. Alongside all of this Ron Naveen with his Oceanites Foundation has been running a crusade to record changes in frequently visited sites with ad hoc grants from NSF, FCO and foundations as well as travel support from IAATO members and a number of operators. It is a tribute to his persistence that we have any data at all.

Contrast this complete lack of interest from any State Party in funding proper research and monitoring to regulate a major industry with their approach to the other major Antarctic industry fishing. There Parties have established a complete management system with its own secretariat, its scientific committee is fed with extensive research data each year commissioned and paid for by State Parties and the decisions of the Commission of CCAMLR, although political, are evidence-led.

Why is there such a difference between the two industries, both of which are capable in different ways of causing major environmental damage? Since many Parties fund research on tourism impacts in their national parks in order to manage them sustainably why cannot they fund such research in Antarctica? Surely they do not expect this to be funded by the tourist companies? Of course, this is not blue skies research but applied research and so might be considered by some to be of less merit and importance. And yet if you look at the proportion of expensive time of Consultative Meetings devoted to science and to tourism you would certainly be struck by how little science is discussed and how much time tourism takes.

The Committee for Environmental Protection appears to think that it needs less independent science and environmental data and advice from SCAR and more provided directly from its own members. Here then is a real challenge. How will the CEP get the data it needs to provide scientifically sound advice on tourism impacts and monitoring? How will it persuade Parties to fund the necessary research and monitoring and how will it be synthesised and assessed? And if this research is not forthcoming how will intelligent and defensible decisions be made to regulate tourism impacts?

DAVID W.H. WALTON 